\title{
Characterization of a molybdenum cofactor biosynthetic gene cluster in Rhodobacter capsulatus which is specific for the biogenesis of dimethylsulfoxide reductase
}

\author{
Peter S. Solomon, ${ }^{1}$ Anthony L. Shaw, ${ }^{1}$ Ian Lane, ${ }^{2}$ Graeme R. Hanson, ${ }^{2}$ \\ Tracy Palmer ${ }^{3}$ and Alastair G. McEwan ${ }^{1}$
}

\author{
Author for correspondence: Alastair G. McEwan. Tel: +6173365 4878. Fax: +61733654620. \\ e-mail : mcewan $(a$ biosci.uq.edu.au
}

\footnotetext{
1,2 Department of

Microbiology ${ }^{1}$ and Centre for Magnetic Resonance ${ }^{2}$, The University of Queensland, Brisbane 4072, Australia

${ }^{3}$ Nitrogen Fixation Laboratory, John Innes Centre, Colney Lane, Norwich NR4 7UH, UK
}

\begin{abstract}
The DMSO reductase of Rhodobacter capsulatus contains a pterin molybdenum cofactor (Moco) and is located in the periplasm. DNA sequence analysis identified four genes involved in the biosynthesis of the Moco (moaA, moaD, moeB and moaC) immediately downstream of the dor (DMSO respiratory) gene cluster. Rhodobacter capsulatus MoaA was expressed in Escherichia coli as a $\mathrm{His}_{6}$-tagged protein. Although, the expressed protein formed inclusion bodies, EPR spectroscopy showed that MoaA contains a [3Fe-4S] cluster. A moaA mutant was constructed and its phenotype indicates that the Moco biosynthetic gene cluster downstream of the dor operon is specific for the biogenesis of DMSO reductase. Two forms of DMSO reductase were purified by immunoaffinity chromatography from the moaA mutant. A mature form of DMSO reductase was located in the periplasm and a precursor form was found in the cytoplasm.
\end{abstract}

Keywords: molybdenum cofactor, dimethylsulfoxide reductase, Rhodobacter capsulatus

\section{INTRODUCTION}

Apart from nitrogenase, all enzymes containing molybdenum form a coherent group known as the molybdenum oxotransferases and hydroxylases (Kisker et al., 1997; Hille, 1996). The common feature of these oxomolybdenum enzymes is the presence of a pterin molybdenum cofactor (Moco). In oxomolybdenum enzymes from eukaryotes the organic component of Moco is a tricyclic pterin derivative known as molybdopterin (MPT) and its carbon side chain ends with a phosphate group. In almost all bacterial oxomolybdenum enzymes the MPT is in a dinucleotide form and this has been revealed in a spectacular fashion via the high resolution crystal structures of DMSO reductase (Schindelin et al., 1996; Schneider et al., 1996; McAlpine et al., 1997), aldehyde oxidoreductase (Romeo et al., 1995) and formate dehydrogenase (Boyington et

Abbreviations: Moco, pterin molybdenum cofactor; MPT, molybdopterin.

The GenBank accession number for the sequence reported in this paper is AF012844. al., 1997). Furthermore, it appears that in formate dehydrogenase and DMSO reductase there are two MPT guanine dinucleotide units per Mo atom. The sulfur atoms of the ene-dithiolate side chains of both MPT guanine dinucleotide moieties are ligands to the Mo centre.

Although it is now established that there is a diversity of nucleotide derivatives of MPT, there is a wealth of biochemical genetic evidence that there is a common pathway of synthesis of MPT (Johnson \& Rajagopalan, $1987 \mathrm{a}, \mathrm{b})$. Much of this information has come from the analysis of pleiotropic mutants of Escherichia coli which are defective in various steps in Moco biosynthesis. These mutants, identified via the chlorate-resistant phenotype (Chl mutants), have been redesignated and at least five distinct loci (moa, mob, mod, moe and mog) are now recognized as genes or gene clusters encoding enzymes involved in synthesis of MPT and its dinucleotide forms. In E. coli the moa locus contains five genes that are involved in the early stages of the synthesis of MPT (Johnson \& Rajagopalan, 1987a, b; Rivers et al., 1993). moeB and moaD are thought to encode proteins involved in the addition of sulfur to these 
moieties, since moeB and moaD mutants accumulate a sulfur-free molecule known as precursor $Z$, derived from the action of MoaABC (Pitterle \& Rajagopalan, 1989). The enzymic step catalysed by MoaABC is still unclear. Although E. coli is an excellent system for the study of oxomolybdenum enzymes and Moco biosynthesis, other systems, notably the purple photosynthetic bacteria Rhodobacter sphaeroides and Rhodobacter capsulatus, are now well-developed. For example, $R$. capsulatus possesses a periplasmic DMSO reductase (McEwan et al., 1991) whose structure is now defined at $1.8 \AA$ resolution (McAlpine et al., 1997), a cytoplasmic xanthine dehydrogenase (Leimkuhler et al., 1998) and in some strains a periplasmic nitrate reductase (McEwan et al., 1984).

Recently, we have completed the sequencing of the dor operon of $R$. capsulatus. This gene cluster encodes proteins involved in DMSO respiration (Shaw et al., 1999). In this paper we describe the analysis of Moco biosynthetic genes which are clustered $3^{\prime}$ to the dor genes of $R$. capsulatus. Analysis of the predicted amino acid sequence of the DMSO structural gene (dorA) (Shaw et al., 1996) revealed that it possesses an unusually long signal peptide which contains the 'twin arginine' motif characteristic of exported proteins which bind complex prosthetic groups (Berks, 1996). It has been suggested that proteins of this type may be secreted via a secretory pathway that is distinct from, or is a modification of, the Sec pathway (Berks, 1996). In this paper the effect of a mutation in moaA on oxomolybdenum enzyme activity has been investigated and the cellular localization of the DMSO polypeptide in this mutant is described.

\section{METHODS}

Bacterial strains and plasmids. Strains and plasmids used during this study are described in Table 1. Typically, $R$. capsulatus strain $37 \mathrm{~b} 4$ was grown phototrophically on RCV medium as described by Weaver et al. (1975). E. coli was grown routinely on LB medium with antibiotics added where required. For the growth of $R$. capsulatus, antibiotic concentrations were $\left(\mu \mathrm{g} \mathrm{ml}^{-1}\right)$ : gentamicin $(\mathrm{Gm}), 5$; tetracycline $(\mathrm{Tc}), 1$. Antibiotic concentrations for $E$. coli growth were ( $\mu \mathrm{g}$ $\mathrm{ml}^{-1}$ ): Gm, 5; Tc, 10; ampicillin (Ap), 100. Plasmid pFR400 harbouring the R. sphaeroides nap gene cluster (Reyes et al., 1996) was a generous gift from Dr Conrado Moreno-Vivian (Universidad de Cordoba, Spain) and was transferred to $R$. capsulatus by conjugation with $E$. coli as described by Masepohl et al. (1988).

DNA sequencing and sequence analysis. The Moco biosynthetic gene cluster of the phagemid pALS1 (Shaw et al., 1996) was sequenced using the dye terminator method using an Applied Biosystems 373A automated sequencer. DNA was sequenced in both directions using primers designed from new sequence information (Brendel \& Trifonov, 1984). Sequence alignments and analysis was performed using programs in the Wisconsin GCG software package version 8.1-UNIX.

Expression of $R$. capsulatus MoaA in E. coli. moaA, located on pALS1, was amplified by PCR with the Expand High Fidelity PCR System (Boehringer Mannheim). The typical reaction was made up as follows: $5 \mu \mathrm{l} 10 \times \mathrm{PCR}$ buffer (Boehringer Mannheim), $1.5 \mathrm{mM} \mathrm{MgCl}_{2}, 0.2 \mathrm{mM}$ each dNTP, $5 \%$ DMSO, $1 \mu \mathrm{M}$ each primer, 1 unit Taq/Pwo DNA polymerase (New England Biolabs) and $50 \mathrm{ng}$ template DNA, made up to $50 \mu \mathrm{l}$ with sterile distilled water. Cycles were performed with an initial 1 min denaturation step at $95^{\circ} \mathrm{C}$ followed by 30 cycles of $94^{\circ} \mathrm{C}$ for $1 \mathrm{~min}, 42^{\circ} \mathrm{C}$ for $1 \mathrm{~min}$ and $72^{\circ} \mathrm{C}$ for $7 \mathrm{~min}$. The product of the PCR amplification was purified using the QIAquick PCR purification kit (QIAGEN). The moaA PCR product was cloned into EcoRI/Bam HI sites of pUC8 to create pJPS2. An Ndel-BamHI fragment of pJPS2 was then cloned into pET $15 \mathrm{~b}$ (Novagen) creating the MoaA expression vector, pJPS4.

For the production of MoaA, pJPS4 was transformed into strain BL21(DE3) and a $200 \mathrm{ml}$ culture of these transformed cells was grown until the $\mathrm{OD}_{600}$ had reached $0 \cdot 6$. IPTG was then added to a concentration of $0.4 \mathrm{mM}$ and the cells were allowed to grow for a further $4 \mathrm{~h}$. The cells were harvested by centrifugation at $5000 \mathrm{~g}$ for $10 \mathrm{~min}$ at $4{ }^{\circ} \mathrm{C}$ before being washed twice in $50 \mathrm{mM}$ Tris $/ \mathrm{HCl}, \mathrm{pH} 8.0$. The cells were disrupted by two passages through a French pressure cell at approximately 11000 p.s.i. Large cell fragments and unbroken cells were removed by centrifugation at $25000 \mathrm{~g}$ for $15 \mathrm{~min}$ at $4{ }^{\circ} \mathrm{C}$. The cell-free extract was stored at $-70^{\circ} \mathrm{C}$ until required.

EPR spectroscopy of MoaA. Inclusion bodies containing MoaA were washed twice with $0.2 \mathrm{mg}$ lysozyme $\mathrm{ml}^{-1} / 1 \mathrm{mM}$ EDTA $/ 1 \mathrm{mg}$ sodium deoxycholate $\mathrm{ml}^{-1}$, followed by two washes of $50 \mathrm{mM}$ Tris/ $\mathrm{HCl}, \mathrm{pH} 8 \cdot 0$. The insoluble MoaA was then resuspended in $300 \mu \mathrm{l} 50 \mathrm{mM}$ Tris/ $\mathrm{HCl}, \mathrm{pH} 8.0$. EPR spectra were measured at X-band on a Bruker ESP300E continuous wave spectrometer loaded with version 3.02 of Bruker ESP300E software. Microwave frequency calibration was performed using an EIP 548B frequency counter, while the magnetic field was calibrated using a Bruker ER-035 M Gauss meter. The liquid helium temperatures $(\mathrm{ca} .2 \mathrm{~K}$ ) required for the measurement of EPR spectra from [ $\mathrm{Fe}-\mathrm{S}]$ clusters were achieved using an Oxford Instruments ESR910 liquid helium flow-through cryostat, in conjunction with an Oxford Instruments ITC-4 variable temperature controller. Computer simulation of EPR spectra were performed using the Sophe computer simulation software suite (Wang \& Hanson, 1995, 1996).

Construction of a moaA mutant. moaA was disrupted by insertion of a $\mathrm{Gm}$ resistance cassette into a BglII site at position 489 in the coding region of moaA. The Gm cassette does not possess a transcription terminator and thus expression of genes downstream of the cassette can occur provided the $\mathrm{Gm}$ cassette is in the correct orientation. A BamHI DNA fragment from pR202I containing the Gm cassette (Hirsch \& Beringer, 1984) was cloned into the BglII site of moaA in pJPS2, creating pJPS7. To ensure the transcription of the genes downstream from moaA would occur the orientation of the $\mathrm{Gm}$ cassette was checked by restriction analysis. The mobilization genes required for successful bacterial conjugation were cloned into the EcoRI site of pJPS7 from pR 459II to create pJPS8. pJPS8 was then transferred by conjugation from E. coli S17-1 to $R$. capsulatus as described by Masepohl et al. (1988), creating $R$. capsulatus 37b4 MAA.

Purification of DMSO reductase using a Protein A HiTrap column. A HiTrap Protein A column (Pharmacia) was equilibrated with $5 \mathrm{ml} 10 \mathrm{mM}$ Tris $/ \mathrm{HCl}, \mathrm{pH} 7 \cdot 5$. Anti-DMSO reductase antibody $(2 \mathrm{mg}$ ) was loaded onto the column and washed again with $5 \mathrm{ml} 10 \mathrm{mM}$ Tris/ $\mathrm{HCl}, \mathrm{pH} 7 \cdot 5$. The cell- 
Table 1. Bacterial strains and plasmids used in this study

\begin{tabular}{|c|c|c|}
\hline Strain/plasmid & Genotype and properties* & Reference or source \\
\hline \multicolumn{3}{|l|}{ R. capsulatus } \\
\hline $37 \mathrm{~b} 4$ & Wild-type & Kaufmann et al. (1984) \\
\hline $37 \mathrm{~b} 4 \mathrm{MAA}$ & moaA::Gm & This work \\
\hline \multicolumn{3}{|l|}{ E. coli } \\
\hline BL21 (DE3) & $\begin{array}{l}\mathrm{F}^{-} \text {ompT } T \text { lon] } h s d S_{\mathrm{B}}\left(\mathrm{r}_{\mathrm{b}}{ }^{-} \mathrm{m}_{\mathrm{b}}{ }^{-}\right) \text {; an } E \text {. coli } \mathrm{B} \\
\text { strain with } \mathrm{DE} 3 \text {, a } \lambda \text { prophage carrying the } \\
\text { T7 RNA polymerase gene; } \mathrm{Ap}^{\mathrm{r}}\end{array}$ & Studier et al. (1990) \\
\hline JM109 & $\begin{array}{l}\text { endA1 recA1 syrA96 thi hsdR17 }\left(\mathrm{r}_{\mathrm{k}}^{-} \mathrm{m}_{\mathrm{k}}{ }^{-}\right) \\
\text {relA1 supE44 } \lambda^{-} \Delta\left(\text { lac-proAB) }\left[\mathrm{F}^{\prime}, \text { traD36 }\right.\right. \\
\left.\text { proAB lacl }{ }^{\mathrm{q}} \mathrm{Z} \Delta \mathrm{M} 15\right]\end{array}$ & Yanisch-Perron et al. (1985) \\
\hline$S 17-1$ & $\begin{array}{l}\mathrm{RP4} 4-2(\mathrm{Tc}:: \mathrm{Mu})(\mathrm{Km}:: \mathrm{Tn} 7) ; \text { integrated into } \\
\text { chromosome }\end{array}$ & Simon et al. (1983) \\
\hline \multicolumn{3}{|l|}{ Plasmids } \\
\hline pALSl & $\begin{array}{l}\text { pBK-CMV phagemid vector containing } R \text {. } \\
\text { capsulatus dor } A ; \mathrm{Km}^{r}\end{array}$ & Shaw et al. (1996) \\
\hline pUC8 & $A p^{r} l a c Z \alpha$ & Vieira \& Messing (1982) \\
\hline pJPS2 & R. capsulatus moaA in pUC8 & This work \\
\hline pET $1.5 b$ & Expression vector & Novagen \\
\hline pJPS4 & R. capsulatus moaA in pET15b & This work \\
\hline pR202I & Plasmid containing Gm cassette & Hirsch \& Beringer (1984) \\
\hline pJPS 8 & moaA:: Gm in pUC8 mob(RP4); $\mathrm{Tc}^{r}$ & This work \\
\hline $\mathrm{pFR}+(10$ & $\begin{array}{l}6.8 \mathrm{~kb} \text { Pst I fragment containing } R \text {. } \\
\text { sphaeroides nap gene cluster in pPHU231 } \\
\mathrm{Mob}^{+} ; \mathrm{Tc}^{\mathrm{r}}\end{array}$ & Reyes et al. (1996) \\
\hline
\end{tabular}

* Km, kanamycin.

free extract of the strain being analysed was then applied to the column and washed with $5 \mathrm{ml} 10 \mathrm{mM}$ Tris $/ \mathrm{HCl}, \mathrm{pH} 7 \cdot 5$, containing $500 \mathrm{mM} \mathrm{NaCl}$. DMSO reductase was eluted from the column using $100 \mathrm{mM}$ glycine, $\mathrm{pH} 2 \cdot 5$, and $250 \mu \mathrm{l}$ fractions collected. Each fraction collection tube contained $250 \mu \mathrm{l} 1 \mathrm{M}$ Tris/ $\mathrm{HCl}, \mathrm{pH} 8 \cdot 0$, to quickly adjust the $\mathrm{pH}$ of the protein from $\mathrm{pH} 2.5$. Presence of DMSO reductase was analysed by following the absorbance of the fractions at $280 \mathrm{~nm}$. The protein-containing fractions were analysed on SDS-PAGE (7.5\% acrylamide; $30: 0.8$ acrylamide/bis-acrylamide) as described by Laemmli (1971).

Enzyme assays. DMSO reductase was assayed as described by McEwan et al. (1985). Protein determination was performed using the bichinconinic acid reagent with bovine serum albumin as a standard (Smith et al., 1985). Nitrate reductase was assayed as for DMSO reductase except that nitrate was used in place of DMSO as the substrate. Xanthine dehydrogenase activity was measured as described by Leimkuhler et al. (1998).

\section{RESULTS}

\section{A Moco biosynthetic gene cluster is located $3^{\prime}$ to the dor gene cluster}

The cloning of $\operatorname{dor} A$ from a $\lambda$ library of $R$. capsulatus genomic DNA and its nucleotide sequence has been reported (Shaw et al., 1996). Further sequence analysis $5^{\prime}$ to dor $A$ has identified genes encoding electron transfer proteins of the DMSO respiratory chain (Shaw et al.,

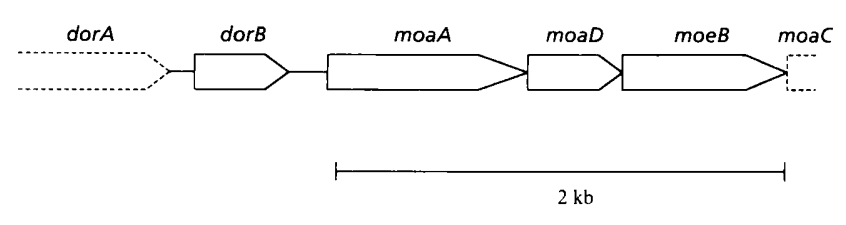

Fig. 1. Organization of the Moco biosynthetic gene cluster identified downstream of dor $B$ of $R$. capsulatus.

1999). A putative transcription terminator $3^{\prime}$ to $\operatorname{dor} A$ has been identified immediately beyond the $\operatorname{dor} A$ stop codon (Fig. 1). Beyond the transcription terminator five ORFs were identified. The first ORF has been named dor $B$; it encodes a putative protein of about $11 \mathrm{kDa}$ and its role in the biogenesis of DMSO reductase is discussed in the accompanying paper (Shaw et al., 1999). A 215 bp intergenic region separates the stop codon of $\operatorname{dor} B$ from four ORFs (Fig. 1). These ORFs were closely linked; the end of the coding sequence of each ORF was only 1 base proximal to the putative translation start site of the next ORF.

DNA sequence analysis of the three additional ORFs showed that they have high sequence similarity to MPT biosynthetic genes. The first ORF was identified as moaA. One base after the stop codon of moaA is the potential start site of another ORF that shows extensive 


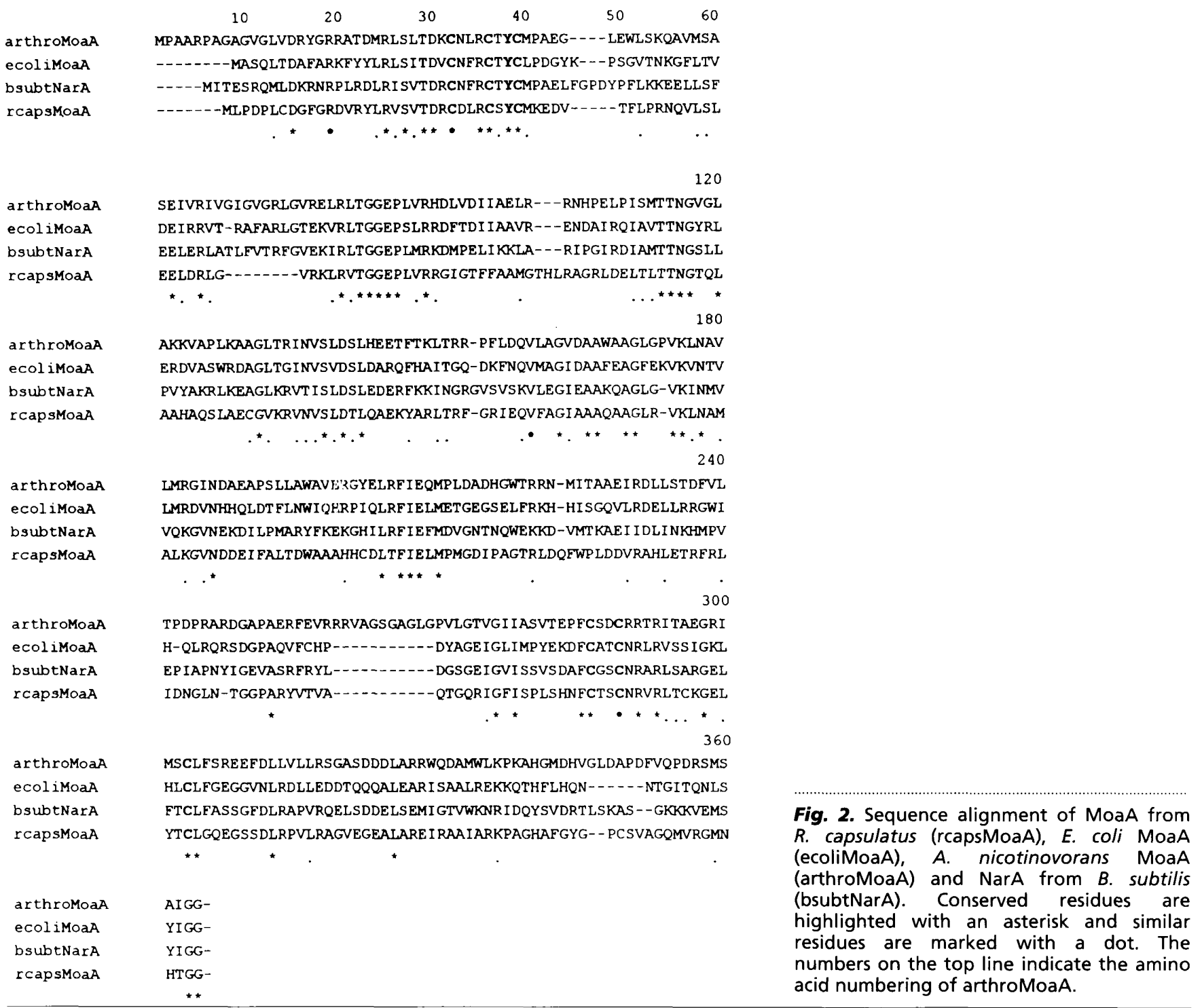

sequence similarity to moaD. The next ORF begins one base ahead of the stop codon of moaD and appears to be another Moco biosynthetic gene, moeB. Beyond moeB, a small region of DNA (150 bases) was sequenced to the end of pALS1 and this exhibits extensive sequence similarity to the MPT biosynthetic gene moaC. No transcription terminators were identified in this MPT biosynthetic gene cluster.

\section{Analysis of the predicted MoaA amino acid sequence}

The ORF identified as moaA encodes a protein of 328 aa with a calculated molecular mass of $35820 \mathrm{Da}$ and $\mathrm{pI}$ of 8.2. MoaA is involved in the formation of an early intermediate in MPT biosynthesis known as precursor $\mathrm{Z}$ (Johnson \& Rajagopalan, 1987a, b). R. capsulatus MoaA shows a high level of sequence similarity to MoaA from E. coli ( $32 \%$ identity) and Arthrobacter nicotinovorans ( $37 \%$ identity) as well as to NarA from Bacillus subtilis $(34 \%)$. Of particular interest is the conservation of the cysteine-rich regions at both the $\mathrm{N}$ and $\mathrm{C}$ termini (Fig. 2), typical of MoaA proteins identified thus far. These cysteine regions are thought to be involved in the formation of an $[\mathrm{Fe}-\mathrm{S}]$ cluster (Menendez et al., 1995).

\section{Analysis of the predicted MoaD and MoeB amino acid sequence}

The second ORF in the MPT biosynthetic gene cluster encodes MoaD. This protein is part of the converting factor, a complex involved in sulfur addition to precursor Z (Pitterle \& Rajagopalan, 1989; Pitterle et al., 1993). The calculated molecular mass and $\mathrm{pI}$ for MoaD are $8895 \mathrm{Da}$ and $4 \cdot 4$, respectively. The MoaD sequence from $R$. capsulatus was found to be $27 \%$ identical to $E$. coli MoaD. No significant sequence similarity was observed between MoaD from R. capsulatus and the $\alpha$ subunit of nitrate reductase A from E. coli as observed for MoaD from E. coli (Rivers et al., 1993). 
(a)

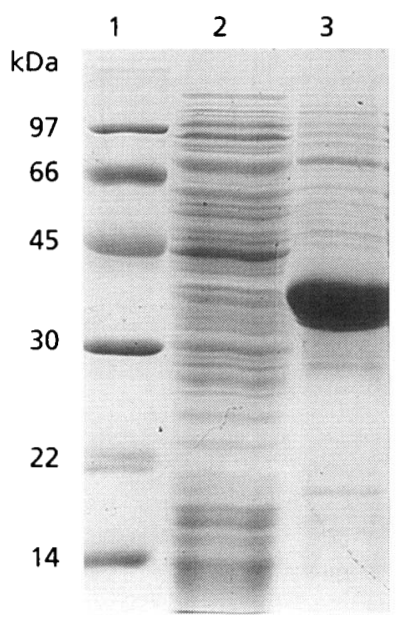

(b)

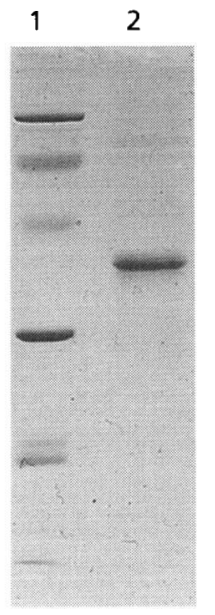

Fig. 3. (a) SDS-PAGE analysis of the expression of $R$. capsulatus MoaA in $E$. coli. Lanes: 1 , molecular mass standards; 2 , soluble fraction; 3, pellet after low speed centrifugation. (b) SDS-PAGE analysis of MoaA used for EPR spectroscopy. Lanes: 1, molecular mass standards; 2 , washed inclusion bodies containing MoaA.

Sequence analysis of the ORF immediately downstream from moaD identified it as moeB. MoeB is responsible for supplying sulfur to the converting factor in the conversion of precursor $\mathrm{Z}$ to MPT (Pitterle \& Rajagopalan, 1989; Pitterle et al., 1993). MoeB comprises 253 aa with a calculated molecular mass of $26 \cdot 6 \mathrm{kDa}$. As expected, the amino acid sequences of MoeB from $R$. capsulatus and E. coli are highly similar (41\% identity). R. capsulatus MoeB was also highly similar to ThiF from E. coli ( $41 \%$ sequence similarity). ThiF is required for the synthesis of thiazole in the thiamine biosynthetic pathway (Vander Horn et al., 1993).

\section{Expression of $R$. capsulatus moaA in E. coli and spectroscopic characterization of MoaA}

The presence of the conserved cysteine residues in MoaA and the sequence similarity of this protein to NifB has led to the suggestion that this protein contains an [Fe-S] cluster (Rivers et al., 1993; Menendez et al., 1995). This has been confirmed in the case of the Arthrobacter MoaA where an [Fe-S] cluster was identified spectroscopically (Menendez et al., 1995). R. capsulatus $\mathrm{His}_{6}$-MoaA was expressed in E. coli as described in Methods. Analysis of cell extracts by SDS-PAGE showed that the recombinant plasmid pJPS4, containing moaA, directed the synthesis of a $38 \mathrm{kDa}$ polypeptide. No $\mathrm{His}_{6}$ MoaA appeared water-soluble but was present as inclusion bodies (Fig. 3a) which formed a pale brown pellet after centrifugation. Varying cell growth conditions, including decreasing the IPTG concentration used for induction of moaA expression and growing cells at $25^{\circ} \mathrm{C}$, were tried in an attempt to obtain soluble MoaA. However, no soluble MoaA was obtained. The inclusion bodies were washed to remove contaminating

material and Fig. 3(b) shows the polypeptide composition of the MoaA-containing sample after these washing steps. This sample was used for EPR spectroscopy.

An X-band EPR spectrum of resting MoaA at $2 \mathrm{~K}$ is shown in Fig. 4 (spectrum A). Resonances around $g=$ 2.01 were observed, typical of a species containing a single unpaired electron. These resonances were not observed above $20 \mathrm{~K}$ and no other resonances were observed over a wide range of magnetic fields $(0-1.5 \mathrm{~T})$. Reduction of the sample with sodium dithionite destroyed the $g=2 \cdot 01 \mathrm{EPR}$ signal, indicating that it is the resting (oxidized) form of MoaA which contains a paramagnetic centre. Computer simulation of spectrum A in Fig. 4 with an $S=1 / 2$ spin Hamiltonian $(H=\beta . B . g . S)$ and the orthorhombic $g$-matrix $\left(g_{1}=2 \cdot 0040, g_{2}=2 \cdot 0154, g_{3}=2 \cdot 0232\right)$ yielded the spectrum shown in Fig. 4 (spectrum b). The g-value anisotropy, line shape and redox characteristics of this spectrum are consistent with a $[3 \mathrm{Fe}-4 \mathrm{~S}]^{1+.0}$ cluster being present in the sample of purified MoaA.

\section{The effect of a moaA mutation on the activity of oxomolybdenum enzymes in $R$. capsulatus}

The clustering of Moco biosynthetic genes and dor genes raised the question of whether the former are specific for expression of the DMSO reductase or for all oxomolybdenum enzymes in $R$. capsulatus. To address this question a moaA mutant was constructed by marker exchange and this resulted in the insertion of a $\mathrm{Gm}$ interposon into the genomic copy of moaA. This $\mathrm{Gm}$ interposon was inserted in an orientation such that there would be transcriptional read-through from the $\mathrm{Gm}$ interposon into the Moco biosynthetic genes that lie downstream of moaA. The specific activity of xanthine dehydrogenase was $0.31 \mathrm{mU} \mathrm{mg}^{-1}$ in wild-type $R$. capsulatus and $0.28 \mathrm{mU} \mathrm{mg}^{-1}$ in the moaA mutant, indicating that the mutation in moaA had little effect on xanthine dehydrogenase activity. In contrast, the activity of DMSO reductase in the moaA mutant $(0.07 \mathrm{mU}$ $\mathrm{mg}^{-1}$ ) was only about $3 \%$ of that found in wild-type cells $\left(2.65 \mathrm{mU} \mathrm{mg}^{-1}\right)$. However, Western blotting of cellfree extracts showed that the level of DMSO reductase polypeptide was essentially the same in wild-type cells and the moaA mutant (data not shown). These data suggested that the moaA gene that had been mutated was specifically required for the biogenesis of holoDMSO reductase but not for other oxomolybdenum enzymes. $R$. capsulatus strain $37 \mathrm{~b} 4$ does not possess a nitrate reductase but can express the periplasmic nitrate reductase (encoded by the nap operon) of $R$. sphaeroides (Solomon, 1998). The level of nitrate reductase activity was similar in wild-type $R$. capsulatus $\left(44.8 \mathrm{mU} \mathrm{mg}^{-1}\right)$ and the moaA mutant $\left(46 \cdot 2 \mathrm{mU} \mathrm{mg}^{-1}\right)$ when the nap genes of $R$. sphaeroides were expressed from a plasmid. These results are consistent with the view that the copy of $m o a A$ that lies downstream of the dor gene cluster must be specific for expression of DMSO reductase. 


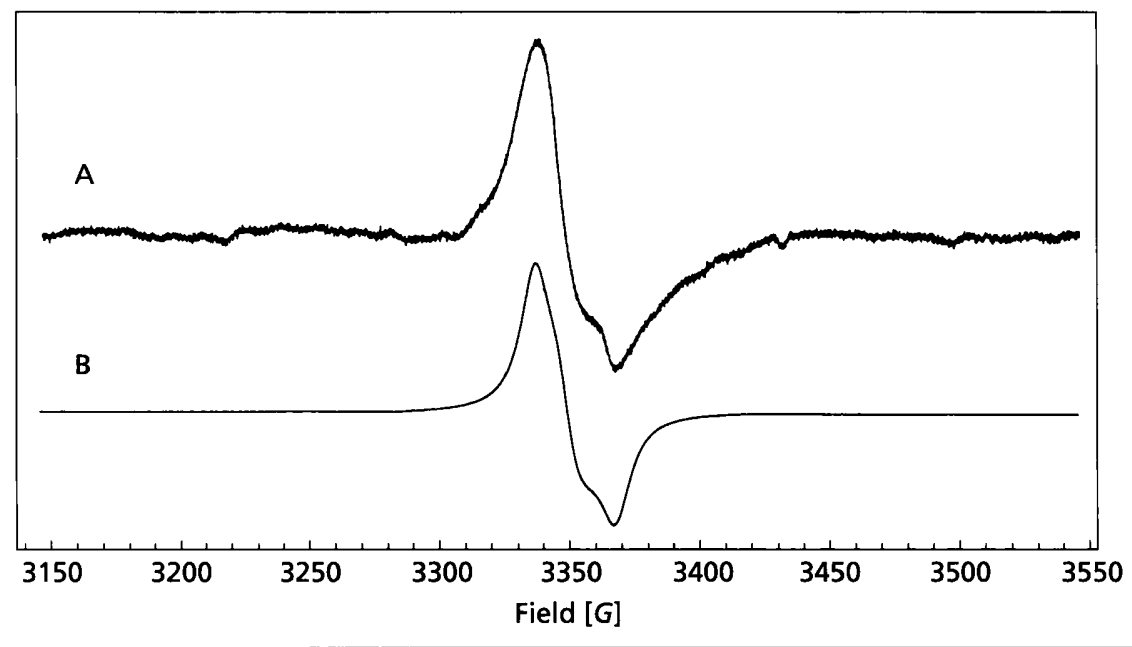

(a)

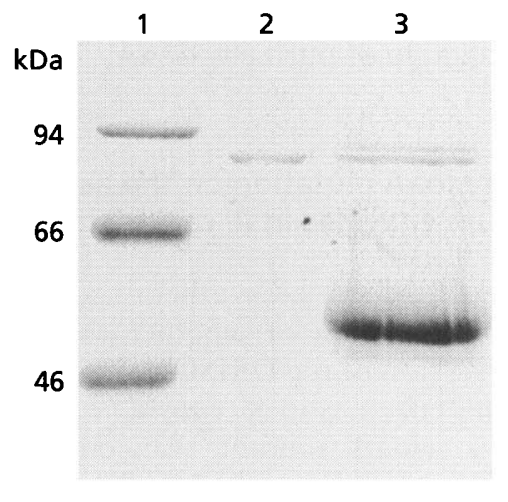

(b)

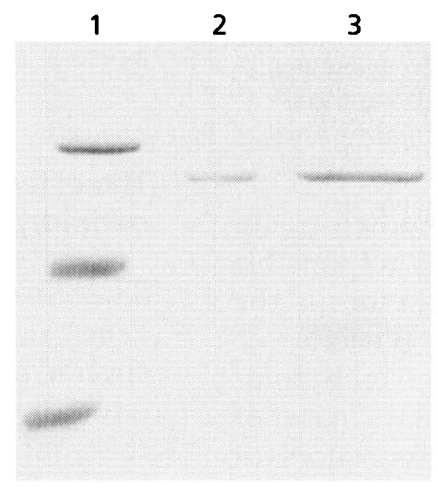

Fig. 4. X-band EPR spectrum of resting $\mathrm{His}_{6}-$ MoaA. (A) Experimental spectrum. (B) Computer simulation. Microwave frequency = $9.4452 \mathrm{GHz}, T=2 \mathrm{~K}$.

(c)

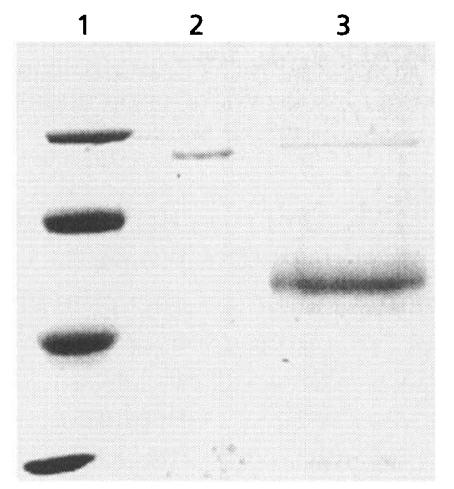

Fig. 5. SDS-PAGE analysis of DMSO reductase purified from cell fractions of the moaA mutant by immunoaffinity chromatography. (a) Lanes: 1, molecular mass standards; 2, purified DMSO reductase standard; 3, eluant containing DMSO reductase from cell-free extracts. (b) Lanes: 1 , molecular mass standards; 2 , purified DMSO reductase standard; 3 , eluant containing DMSO reductase from a periplasmic fraction. (c) Lanes: 1, molecular mass standards; 2 , purified DMSO reductase standard; 3 , eluant containing DMSO reductase from a cytoplasmic fraction.

\section{Synthesis and secretion of the DMSO reductase polypeptide in a moaA mutant}

Previous studies of the secretion of DMSO reductase from R. sphaeroides (Yoshida et al., 1991) have shown that molybdate deficiency or a mutation in the Moco biosynthetic pathway leads to accumulation of the DMSO reductase polypeptide inside the cell. The moaA mutant of $R$. capsulatus generated in this study allowed us to analyse the secretion of the DMSO reductase polypeptide in a defined genetic background. A Western blot of cell fractions of the moaA mutant was probed with anti-DMSO reductase antibody. DMSO reductase polypeptide was found in both the cytoplasmic and periplasmic fractions of the cell with no detectable protein in the membrane (data not shown). The results indicated that the moaA mutation was affecting the secretion of DMSO reductase and this led us to analyse the DMSO reductase polypeptides more closely. AntiDMSO reductase antibody was bound to a $\mathrm{Hi}$-Trap Protein A affinity column and this was used to purify
DMSO reductase polypeptides from the moaA mutant and wild-type cells. Fig. 5 shows a SDS-PAGE analysis of polypeptides eluted from the antibody affinity column at $\mathrm{pH} 2.5$ during the chromatography of cell-free extracts and cell fractions. Apart from polypeptides corresponding to IgG light and heavy chains, two polypeptides in the molecular mass range of DMSO reductase were purified from the cell extracts of the moaA mutant (Fig. 5a, lane 3). The smaller polypeptide had an identical mobility to the polypeptide purified from strain $37 \mathrm{~b} 4$ (Fig. 5a, lane 2) while the larger polypeptide had a molecular mass of about $90 \mathrm{kDa}$. Analysis of a periplasmic fraction using the same immunoaffinity chromatography system showed that the smaller polypeptide could be purified from this cellular fraction (Fig. 5b, lane 3) while the large polypeptide could be purified from the cytoplasmic fraction (Fig. 5c, lane 3). In wild-type cells only the smaller form of DMSO reductase was detected and it was located in the periplasm (data not shown). 


\section{DISCUSSION}

In this paper we have described the analysis of part of a Moco biosynthetic gene cluster in $R$. capsulatus which appears to be specific for the biogenesis of DMSO reductase. The observation that the moaA mutant generated in this study continued to synthesize active nitrate reductase and xanthine dehydrogenase strongly suggests that there is a second moaA gene in $R$. capsulatus. It seems likely that the other components of the Moco biosynthetic gene cluster that have been sequenced will also be specific for the biogenesis of DMSO reductase. The question of whether all components of the Moco biosynthetic pathway are duplicated was not addressed in this study. However, copies of moa C, moaD and moeB that are not linked to the dor operon have been identified in $R$. capsulatus (S. Leimkuhler \& W. Klipp, personal communication).

The presence of two copies of moaA in A. nicotinovorans is established; one copy of moaA is located on a plasmid along with the structural gene for the oxomolybdenum enzyme nicotine dehydrogenase (ndh). This plasmid-borne copy of moaA is essential for formation of nicotine dehydrogenase but not for other oxomolybdenum enzymes in this bacterium (Menendez et al., 1995). In Methanobacterium formicicum a putative moaA gene is located upstream of the formate dehydrogenase operon (White \& Ferry, 1992). A moaA homologue in B. subtillis, known as narA, is immediately downstream of narQ (Glaser et al., 1995). Thus, the linkage of moaA to the dor operon in R. capsulatus is not unusual, although it has not been observed for oxomolybdenum enzymes in E. coli. At this stage we cannot rule out the possibility that transcription of the other Moco biosynthetic genes can initiate downstream of $m o a A$, but no obvious sequence corresponding to a promoter has been identified. The available data suggest that at least moaA, moaD, moeB and moaC, which lie downstream of the dor gene cluster, are specific for the biogenesis of DMSO reductase. In the absence of their expression a low level of DMSO reductase activity was observed, consistent with the presence of a second complement of Moco biosynthetic genes which have a role in synthesis of Moco for insertion into all oxomolybdenum enzymes. The reason why DMSO reductase requires a specific set of Moco biosynthetic genes is not clear but this enzyme is a major respiratory protein in the periplasm of $R$. capsulatus. The above observations raise the question of whether the dor genes and moaA, moaD and moeB form an operon? Although we have not yet performed detailed transcriptional studies, experiments with transcriptional lac fusions suggest that there might be transcriptional coupling of the dor genes and the Moco biosynthetic genes (P. S. Solomon \& A. G. McEwan, unpublished observations).

MoeB and MoaD are thought to have a role in the incorporation of sulfur atoms into the MPT precursor, thereby producing the ene-dithiolate moiety that binds Mo. In moeB and moaD mutants an MPT precursor which lacks sulfur atoms, known as precursor $\mathrm{Z}$, has been identified (Pitterle \& Rajagopalan, 1989; Pitterle et al., 1993). Precursor $Z$ cannot be detected in a moaA mutant and this has led to the view that MoaA is involved in one of the earliest steps in MPT synthesis (Johnson \& Rajagopalan, 1987a, b). Recently, the early steps in MPT synthesis have been investigated in E. coli and it has been concluded that GTP is the precursor of MPT and that the pathway proceeds via steps that are distinct from those known for pteridine synthesis (Wuebbens \& Rajagopalan, 1995).

The sequence of MoaA exhibits two highly conserved cysteine-rich segments towards the $\mathrm{N}$ and $\mathrm{C}$ termini of the protein. Site-directed mutagenesis studies of MoaA from A. nicotinovorans have shown that all cysteines are essential for MoaA function with two from each segment suggested to be required for the formation of an $[\mathrm{Fe}-\mathrm{S}]$ cluster in A. nicotinovorans MoaA (Menendez et al., 1995). The EPR spectroscopy of the $\mathrm{His}_{6}$-MoaA ( $R$. capsulatus) produced in E. coli confirms the presence of this [Fe-S] cluster. The EPR spectrum of oxidized MoaA can be assigned to a $[3 \mathrm{Fe}-4 \mathrm{~S}]^{1+}$ cluster on the basis of the observed g-value anisotropy, temperature dependence and the loss of the spectrum upon reduction with sodium dithionite (Kent et al., 1980; Kutcha et al., 1986). The $[\mathrm{Fe}-\mathrm{S}]$ cluster within oxidized MoaA cannot be $[2 \mathrm{Fe}-2 \mathrm{~S}]^{2+, 1+}$ or $[4 \mathrm{Fe}-4 \mathrm{~S}]^{2+.1+}$ as the oxidized forms of these clusters are EPR-silent. The $g$-value anisotropy and temperature dependence is inconsistent with an oxidized $[4 \mathrm{Fe}-4 \mathrm{~S}]^{3+.2+}$ cluster (Pilbrow \& Hanson, 1993).

Menendez et al. (1996) suggested that MoaA may be an oxidoreductase or that it is involved in sulfur donation to the converting factor (MoaD and MoeB). The idea of MoaA participating in the donation of sulfur to the converting factor seems unlikely. A MoaA mutant is unable to produce precursor $Z$, strongly indicating that MoaA is involved in the synthesis of precursor $Z$ from GTP (Johnson \& Rajagopalan, 1987a, b; Pitterle \& Rajagopalan, 1989). Also, it has been clearly established with conclusive experiments by Rajagopalan and coworkers that MoeB (activating factor) is responsible for the donation of sulfur to the converting factor (Pitterle \& Rajagopalan, 1989). Recently, it has become clear that $[\mathrm{Fe}-\mathrm{S}]$ clusters have a multiplicity of functions (Beinert et al., 1997). Although we have identified a [3Fe-4S] cluster in MoaA, it is possible that, like aconitase, the active form of MoaA may contain a [4Fe-4S] cluster. One possibility is that an $\mathrm{Fe}$ atom in the $[4 \mathrm{Fe}-4 \mathrm{~S}]$ cluster of MoaA acts as a Lewis acid and promotes a hydration or dehydration reaction which is proposed to occur during the conversion of a phosphorylated guanosine precursor to precursor $\mathrm{Z}$ (Wuebbens \& Rajagopalan, 1995).

The involvement of MoeB in the addition of sulfur to precursor $\mathrm{Z}$ in $E$. coli was elucidated over 5 years ago (Pitterle et al., 1993). As mentioned in the results section, MoeB from $R$. capsulatus not only exhibited high similarity to MoeB from E. coli, but also to the thiamine biosynthetic protein, ThiF, from E. coli. Vander Horn et al. (1993) determined that ThiF was involved in syn- 
thesizing a precursor to thiamine, 4-methyl-5-( $\beta$-hydroxyethyl)thiazole (THZ) from 1-deoxy-D-threo-2pentulose in a reaction also requiring tyrosine and cysteine. Interestingly, among other reactions, the synthesis of THZ involves the addition of a sulfur with the source of that sulfur identified as cysteine (DeMoll \& Shive, 1985). Recently, it has been shown that ThiF catalyses the adenylation of another protein by ATP, ThiS, thereby activating this protein for sulfur transfer (Taylor et al., 1998).

The results presented in Fig. 5 show that in the absence of moaA downstream of $\operatorname{dor} A$, a precursor form of DMSO reductase appears to accumulate in the cytoplasm. The activity measurements in this study revealed only a very low level of active DMSO reductase in the periplasm. However, it appeared that about half of the DMSO reductase polypeptide produced was secreted. In contrast, in $E$. coli a mutation in moaA results in a complete absence of mature periplasmic TorA with only the precursor being present in the cytoplasm (Santini et al., 1998). It is suggested that in the R. capsulatus MoaA mutant some secretion of holo-DMSO reductase can occur because, unlike the MoaA mutant of E. coli, Moco biosynthesis can occur at a low level in this mutant. We have observed that the precursor form of DMSO reductase is unstable (P. S. Solomon \& A. G. McEwan, unpublished observations) and hence the level of cytoplasmic precursor may be underestimated in our experiments. Pulse-chase experiments would be required to confirm this view.

The traditionally held view of secretion is that periplasmic proteins are exported in an unfolded state via the Sec system (Pugsley, 1993; Driessen, 1994). However, Berks (1996) suggested that the export of periplasmic proteins containing a complex prosthetic group such as Moco would require a novel secretory pathway and support for this view has come from the observation that the export of TMAO reductase in E. coli is Secindependent (Santini et al., 1998). Recently, a system for the export of folded proteins containing a 'twin arginine' motif has been identified in E. coli (Sargent et al., 1998; Weiner et al., 1998). This system is encoded by the tat operon (also known as the $m t t$ operon) and it is homologous to the Sec-independent protein translocation system (HCF106) found in chloroplasts (Settles et al., 1997). It has already been noted that the homologues of HCF106 have been found in a number of bacterial genomes and thus it seems likely that the secretion of DMSO reductase in $R$. capsulatus will occur via this Secindependent system.

\section{ACKNOWLEDGEMENTS}

This work was supported by grants from the Australian Research Council and the University of Queensland (A.G. M. and G.R.H.) and by an Australian Postgraduate Award (A.L.S.).

\section{REFERENCES}

Beinert, H., Holm, R. H. \& Munck, E. (1997). Iron-sulfur clusters : Nature's modular, multipurpose structures. Science 277, 653-659.
Berks, B. C. (1996). A common export pathway for proteins binding complex redox cofactors? Mol Microbiol 22, 393-404.

Boyington, J. C., Gladyshev, V., Khangulov, S. V., Stadtman, T. C. \& Sun, P. D. (1997). Crystal structure of formate dehydrogenase $\mathrm{H}$ : catalysis involving $\mathrm{Mo}$, molybdopterin and an $\mathrm{Fe}_{4} \mathrm{~S}_{4}$ cluster. Science 275, 1305-1308.

Brendel, V. \& Trifonov, E. N. (1984). A computer algorithm for testing potential prokaryotic terminators. Nucleic Acids Res 12, $4411-4427$.

DeMoll, E. \& Shive, W. (1985). Determination of the metabolic origin of the sulfur atom in thiamine of Escherichia coli by mass spectrometry. Biochem Biophys Res Commun 132, 217-222.

Driessen, A. J. M. (1994). How proteins cross the bacterial cytoplasmic membrane. J Membr Biol 142, 145-159.

Glaser, P., Danchin, A., Kunst, F., Zuber, P. \& Nakano, M. M. (1995). Identification and isolation of a gene required for nitrate assimilation and anaerobic growth of Bacillus subtilis. J Bacteriol 177, 1112-1115.

Hille, R. (1996). The mononuclear molybdoenzymes. Chem Rev 96, 2757-2816.

Hirsch, P. R. \& Beringer, J. E. (1984). A physical map of pPH1J1 and pJB4JI. Plasmid 12, 139-141.

Johnson, J. L. \& Rajagopalan, K. V. (1987a). In vitro synthesis of molybdopterin. J Bacteriol 169, 110-116.

Johnson, J. L. \& Rajagopalan, K. V. (1987b). Involvement of chlA, chlE, chlM and chlN loci in Escherichia coli molybdopterin biosynthesis. J Bacteriol 169, 117-125.

Kaufmann, N., Hudig, H. \& Drews, G. (1984). Transposon Tn5 mutagenesis of genes for the photosynthetic apparatus in $R$ bodopseudomonas capsulata. Mol Gen Genet 198, 153-158.

Kent, T. A., Huynh, B. H. \& Munck, E. (1980). Iron-sulfur proteins: spin coupling models for three-iron clusters. Proc Natl Acad Sci USA 77, 6574-6576.

Kisker, C., Schindelin, H. \& Rees, D. C. (1997). Molybdenum cofactor-containing enzymes: structure and mechanism. Annu Rev Biochem 66, 233-267.

Kutcha, R. D., Hanson, G. R., Holmquist, B. \& Abeles, R. H. (1986). $\mathrm{Fe}-\mathrm{S}$ centres in lactyl-CoA dehydratase. Biochemistry 25, 7302-7307.

Laemmli, U. K. (1970). Cleavage of structural proteins during the assembly of the head of bacteriophage T4. Nature 227, 680-685.

Leimkuhler, S., Kern, P. S., Solomon, P. S., McEwan, A. G., Schwarz, G., Mendel, R. R. \& Klipp, W. (1998). Xanthine dehydrogenase from the phototrophic purple bacterium Rhodobacter capsulatus is more similar to its eukaryotic counterparts than to prokaryotic molybdoenzymes. Mol Microbiol 27, 853-869.

McAlpine, A. S., McEwan, A. G., Shaw, A. L. \& Bailey, S. (1997). Molybdenum active centre of DMSO reductase from $R$ hodobacter capsulatus: crystal structure of the oxidised enzyme at $1.82 \AA$ resolution and the dithionite-reduced enzyme at $2.8 \AA$ resolution. J Biol Inorg Chem 2, 690-701.

McEwan, A. G., Jackson, J. B. \& Ferguson, S. J. (1984). Rationalisation of the properties of nitrate reductases from $R$ hodopseudomonas capsulata. Arch Microbiol 137, 344-349.

McEwan, A. G., Wetzstein, H. G., Ferguson, S. J. \& Jackson, J. B. (1985). Periplasmic location of the terminal oxidoreductase in trimethylamine- $\mathrm{N}$-oxide and dimethylsulphoxide respiration in the photosynthetic bacterium Rhodopseudomonas capsulata. Biochim Biophys Acta 806, 410-417. 
McEwan, A. G., Ferguson, S. J. \& Jackson, J. B. (1991). Purification and properties of dimethylsulphoxide reductase from $R$ hodobacter capsulatus. Biochem J 207, 305-307.

Masepohl, B., Klipp, W. \& Puhler, A. (1988). Genetic characterisation and sequence analysis of the duplicated nif $A /$ nifB gene region of Rhodobacter capsulatus. Mol Gen Genet 212, 27-37.

Menendez, C., Igloi, G., Henninger, H. \& Brandsch, R. (1995). A pAO1-encoded molybdopterin cofactor gene (moaA) of Arthrobacter nicotinovorans: characterisation and site-directed mutagenesis of the encoded protein. Arch Microbiol 164, 142-151.

Menendez, C., Sibert, D. \& Brandsch, R. (1996). MoaA of Arthrobacter nicotinovorans pAO1 involved in Mo-pterin cofactor biosynthesis is an Fe-S protein. FEBS Lett 391, 101-103.

Pilbrow, J. R. \& Hanson, G. R. (1993). Electron paramagnetic resonance. Methods Enzymol 227, 330-353.

Pitterle, D. M. \& Rajagopalan, K. V. (1989). Two proteins encoded at the $c h / A$ locus constitute the converting factor of Escherichia coli chlA1. J Bacteriol 171, 3373-3378.

Pitterle, D. M., Johnson, J. L. \& Rajagopalan, K. V. (1993). The biosynthesis of molybdopterin. Purification and characterization of the converting factor. J Biol Chem 268, 13506-13509.

Pugsley, A. G. (1993). The complete general secretory pathway in Gram-negative bacteria. Microbiol Rev 57, 10-108.

Reyes, F., Roldan, M. D., Klipp, W., Castillo, F. \& Moreno-Vivian, C. (1996). Isolation of periplasmic nitrate reductase genes from Rhodobacter sphaeroides DSM 158: structural and functional differences among prokaryotic nitrate reductases. Mol Microbiol 19, 1307-1.318.

Rivers, S. L., McNairn, E., Blasco, F., Giordano, G. \& Boxer, D. H. (1993). Molecular genetic analysis of the moa operon of Escherichia coli K-12 required for molybdenum cofactor biosynthesis. Mol Microbiol 8, 1071-1081.

Romeo, M. J., Archer, M., Moura, J. J. G., LeGall, J., Engh, R., Schneider, M., Hof, P. \& Huber, R. (1995). Crystal structure of the xanthine oxidase-related aldehyde oxidase from $D$. gigas. Science 270, 1170-1176.

Santini, C.-L., Ize, B., Chanal, A., Muller, M., Giordano, G. \& Wu, L.-F. (1998). A novel Sec-independent periplasmic translocation pathway in Escherichia coli. EMBO J 17, 101-112.

Sargent, F., Bogsch, E. G., Stanley, N. R., Wexler, M., Robinson, C., Berks, B. C. \& Palmer, T. (1998). Overlapping functions of components of a bacterial Sec-independent protein export pathway. EMBO J 17, 3640-3650.

Schindelin, H., Kisker, C., Hilton, J., Rajagopalan, K. V. \& Rees, D. C. (1996). Crystal structure of DMSO reductase: Redox-linked changes in molybdopterin coordination. Science 272, 1615-1620.

Schneider, F., Lowe, J., Huber, R., Schindelin, H., Kisker, C. \& Knablein, J. (1996). Crystal structure of dimethylsulfoxide reductase from Rhodobacter capsulatus at $1.88 \AA$ resolution. $J$ Mol Biol 263, 53-69.

Settles, A. M., Yonetani, A., Baron, A., Bush, D. R., Cline, K. \& Martiensson, R. (1997). Sec-independent protein translocation by the maize Hcf106 protein. Science 278, 1467-1470.

Shaw, A. L., Hanson, G. R. \& McEwan, A. G. (1996). Cloning and sequence analysis of the dimethylsulfoxide reductase structural gene from Rhodobacter capsulatus. Biochim Biophys Acta 1276, 176-180.

Shaw, A. L., Leimkuhler, S., Klipp, W., Hanson, G. R. \& McEwan,
A. G. (1999). Mutational analysis of the dimethylsulfoxide respiratory (dor) operon of Rhodobacter capsulatus. Microbiology 145, 1409-1420.

Simon, R., Priefer, U. \& Puhler, A. (1983). A broad host range mobilization system for in vivo genetic engineering: transposon mutagenesis in Gram negative bacteria. Bio/Technology 1, 784-791.

Smith, P. K., Krohn, R. I., Hermanson, G. T., Maliia, A. K., Gartner, F. H., Provenzano, M. D., Fujimoto, E. K., Goeke, N. M., Olson, B. J. \& Klenk, D. C. (1985). Measurement of protein using bicinchoninic acid Anal Biochem 150, 76-85.

Solomon, P. S. (1998). Characterisation of the pterin molybdenum cofactor in dimethylsulfoxide reductase of Rhodobacter capsulatus and its biogenesis. PhD thesis, University of Queensland, Australia.

Studier, F. W., Rosenberg, A. H., Dunn, J. J. \& Dubendorff, J. W. (1990). Use of T7 RNA polymerase to direct expression of cloned genes. Methods Enzymol 185, 60-89.

Taylor, S. V., Kelleher, N. L., Kinsland, C., Chiu, H.-J., Costello, C. A., Backstrom, A. D., McLafferty, F. W. \& Begley, T. P. (1998). Thiamin biosynthesis in Escherichia coli. J Biol Chem 273, 16555-16560.

Vander Horn, P. B., Backstrom, A., Stewart, V. \& Begley, T. P. (1993). Structural genes for thiamine biosynthetic enzymes (thiCEFGH). J Bacteriol 175, 982-992.

Vieira, J. \& Messing, J. (1982). The pUC plasmids, an M13mp7derived system for insertion mutagenesis and sequencing with synthetic universal primers. Gene 19, 259-268.

Wang, D. \& Hanson, G. R. (1995). A new method for simulating randomly oriented powder spectra in magnetic resonance: The Sydney Opera House (SOPHE) method. J Magn Reson A 117, $1-8$.

Wang, D. \& Hanson, G. R. (1996). New methodologies for computer simulations of paramagnetic resonance spectra. Appl Magn Reson 11, 401-415.

Weaver, P. F., Wall, J. D. \& Gest, H. (1975). Characterisation of Rhodopseudomonas capsulata. Arch Microbiol 105, 207-216.

Weiner, J. H., Bilous, P. T., Shaw, G. M., Lubitz, S. P., Frost, L., Thomas, G. H., Cole, J. H. \& Turner, R. J. (1998). A novel and ubiquitous system for membrane targeting and secretion of cofactor-containing proteins. Cell 93, 93-101.

White, W. B. \& Ferry, J. G. (1992). Identification of formate dehydrogenase-specific mRNA species and nucleotide sequence of the $f d h C$ gene of Methanobacterium formicicum. J Bacteriol 174, 4997-5004.

Wuebbens, M. M. \& Rajagopalan, K. V. (1995). Investigation of the early steps of molybdopterin biosynthesis in Escherichia coli through the use of in vivo labelling studies. J Biol Chem 270, 1082-1087.

Yanisch-Perron, C., Vieira, J. \& Messing, J. (1985). Improved M13 phage cloning vectors and host strains: nucleotide sequences of the M13mp18 and pUC19 vectors. Gene 33, 103-119.

Yoshida, Y., Takai, M., Satoh, T. \& Takami, S. (1991). Molybdenum requirement for translocation of diemethylsulfoxide reductase to the periplasmic space in a photodenitrifier Rhodobacter sphaeroides f. sp. denitrificans. J Bacteriol 173, 3277-3281.

Received 5 January 1999; revised 1 February 1999; accepted 23 February 1999. 